\title{
Heterosis studies in rice for the identification of better hybrids for Telangana, India
}

\section{A. Srijan *, S. Sudheer Kumar, Ch. Damodar Raju, R. Jagadeeshwar}

Department of Genetics and Plant Breeding, Professor Jayashankar Telangana State Agricultural University, College of Agriculture, Rajendranagar-500030 (TG), INDIA

*Corresponding author. E-mail: srijan.ambati1@gmail.com

Received: May 23, 2015; Revised received: October 7, 2015; Accepted: February 10, 2016

\begin{abstract}
In the present study, 23 elite rice genotypes were test crossed with IR 58025A and based on which, 12 restorer lines viz., Rajendra, MTU 1010, IR 64, KNM 118, NLR 33358, Satya, Varalu, RNR 15048, RNR 15038, Tellahamsa, RNR(RK) 28 and RNR(RK) 53 were identified during Kharif- Rabi 2013-14. Then, three CMS lines viz., IR 58025A, IR 68902A and IR 72081A were crossed with these identified 12 restorer lines to produce 36 hybrids in line $x$ tester mating design and were evaluated along with standard hybrid check, PA 6129 at Rice Research Centre, Rajendranagar, during Kharif 2014 to find out the best heterotic combinations in terms of grain yield and yield component characters. The degree of heterosis varied from trait to trait. Out of 36 hybrids studied, the significant standard heterosis for grain yield is observed in 3 hybrids, over best check PA 6129, viz., IR 58025A $\times$ MTU 1010 (18.25), IR 68902A × RNR 15038 (14.59) and IR 72081A × RNR 15038 (9.57). The best experimental hybrid IR $58025 \mathrm{~A} \times$ MTU 1010 recorded average heterosis (78.26) and heterobeltiosis (64.37). These three experimental hybrids can be further evaluated over locations for large scale commercialization in Telangana.
\end{abstract}

Keywords: Heterosis, Heterobeltiosis, Rice and Standard heterosis

\section{INTRODUCTION}

Rice (Oryza sativa L.) is the most important staple food crop for more than 60 per cent of the global population and forms the cheapest source of food energy and protein. India has the largest acreage under rice at $44 \mathrm{M}$. ha $(22 \%$ of cropped area) with annual production of 106.65 MT in the year 2013-14 as per Agricultural Statistics Division, Directorate of Economics \& Statistics, Department of Agriculture \& Cooperation. To make the India self-sufficient in rice and to meet future food requirements, there is a need to improve the productivity every year by almost 2 MT (Raju et $a l ., 2014)$. Results of the hybrid rice commercialization program in the China look promising. China has been able to produce 200 million tonnes rice annually from 30 million hectares. Following China's success in the commercialization of hybrid rice, India was one of the countries to start applied strategic research programme on hybrid rice. The area planted to hybrid rice in the country was around 2.5 million hectares during 2013 as per FAORAP and APSA (2014). It is mainly cultivated in the eastern Indian states of Uttar Pradesh, Jharkhand, Chhattisgarh, and Bihar and has contributed 3-4 million tonnes of additional rice to India's total rice production. As a result of concerted efforts for more than two decades, a total of 72 hybrids have been released for commercial cultivation and all the hybrids released in the country are based on the three- line breeding system as per draft proceedings of Indian Institute of Rice Research (IIRR)-2015. The success of hybrid rice programme depends upon the magnitude of heterosis which also helps in the identification of potential cross combinations to be used in the conventional breeding programme to create wide array of variability in the segregating generations (Krishna Veni and Sobha Rani, 2003). With the objective to identify potential cross combinations, 36 hybrids were developed using CMS (Cytoplasmic Male Sterile) lines system and studied for yield and yield contributing characters in the present investigation.

\section{MATERIALS AND METHODS}

Fertility restoration studies carried out for 23 elite lines by test crossing with single tester IR 58025A during Kharif and Rabi 2013-14. From the results of fertility restoration, 12 lines (i.e., Rajendra, MTU 1010, IR 64, KNM 118, NLR 33358, Satya, Varalu, RNR 15048, RNR 15038, Tellahamsa, RNR(RK) 28, RNR(RK) 53) with more than $75(\%)$ fertility restoration were selected to study the heterosis. The 12 lines were crossed with 3 CMS lines (IR 72081A, IR 68902A and IR 58025A) to develop 36 hybrids by adopting line $\times$ tester mating design given by Kempthorne (1957). The 15 parents and 36 hybrids developed along with a single hybrid check PA 6129 were evaluated in randomized block design with a spacing of $20 \times 15 \mathrm{~cm}$ at Rice Research Centre, Rajendranagar during Kharif 2014. 
All the recommended practices were followed to raise and maintain healthy crop. Observations were recorded for days to 50 per cent flowering, plant height, panicle length, panicle weight, number of productive tillers/ plant, number of unproductive tillers/plant, flag leaf length, flag leaf width, spikelet fertility\%, number of filled grains per panicle, grain yield per plant, productivity/day, 1000 grain weight, grain length, grain breadth and length-breadth ratio. Data obtained was subjected to analysis of variance and heterosis, heterobeltiosis, standard heterosis over high yielding hybrid check PA 6129 were computed as given by Liang et al. (1971) and expressed in percentage as follows:

Heterosis over mid parent: Heterosis was expressed as per cent increase or decrease observed in the $F_{1}$ over the mid-parent as per the following formula.

$$
\text { Heterosis }(\%)\left(\mathrm{h}_{1}\right)=\frac{\overline{F_{1}}-\overline{M P}}{\overline{M P}} \times 100
$$

Where,

$$
\begin{aligned}
& \overline{F_{1}}=\text { Mean of } \mathrm{F}_{1} \\
& \overline{\mathrm{MP}}=\text { Mean of mid parents }
\end{aligned}
$$

Heterosis over better parent: Heterobeltiosis was expressed as per cent increase or decrease observed in $F_{1}$ over the better parent as per the formula.

Heterobeltiosis $\%\left(\mathrm{~h}_{2}\right)=\quad \frac{\overline{F_{1}}-\overline{B P}}{\overline{B P}} \times 100$

Where,

$$
\overline{\mathrm{BP}}=\text { Mean of better parent }
$$

Heterosis over standard checks: Standard heterosis was expressed as per cent increase or decrease observed in $\mathrm{F}_{1}$ over standard checks.

$$
\text { Standard heterosis } \%\left(\mathrm{~h}_{3}\right)=\frac{\bar{F}_{1}-\text { Mean of check }}{\text { Mean of check }} \times 100
$$

\section{RESULTS AND DISCUSSION}

Analysis of variance revealed significant difference for all treatments. It indicates that there is sufficient diversity among the genotypes. So, further heterotic studies were carried out. For days to $50 \%$ flowering, the standard heterosis ranged from -17.69 (IR 72081A $\times \mathrm{KNM}$ 118 ) to 2.53 (IR 58025A $\times$ Tellahamsa), when compared with check PA 6129. Early maturing hybrids are desirable as they produce more yields per day and fit well in multiple cropping systems. Out of 36 hybrids, 28 hybrids showed significant negative standard heterosis. For plant height, the standard heterosis ranged from $16.15($ IR $68902 \mathrm{~A} \times \mathrm{RNR}(\mathrm{RK}) 53)$ to 17.69 (IR $58025 \mathrm{~A} \times \mathrm{RNR} 15038)$, when compared with check PA 6129. Short plant type is an important trait of hybrid to withstand lodging. Out of 36 hybrids, 10 hybrids showed significant negative standard heterosis. For panicle length, standard heterosis ranged from -
16.39 (IR 58025A $\times$ RNR 15048) to 21.31(IR 68902A $\times$ IR 15038), when compared with check PA 6129. Hybrids are generally characterized by having longer panicles, indicating their efficiency in partitioning assimilates into reproductive parts. Out of 36 hybrids, three hybrids showed significant positive standard heterosis. For panicle weight, standard heterosis ranged from $-45.35($ IR 72081A $\times$ Satya) to $57.70($ IR 58025A $\times$ MTU 1010), when compared with check PA 6129 (Table 1).

Panicle weight is positively associated with grain yield and is known to contribute grain yield via more number of filled grains. Out of 36 hybrids, 11 hybrids showed significant positive standard heterosis. For number of productive tillers/ plant, standard heterosis ranged from -39.39 (IR 58025A $\times$ Rajendra) to 54.55(IR 72081 A $\times$ Satya), when compared with check PA 6129 . Number of productive tillers per plant is known to directly contribute towards grain yield and can be exploited. More the number of productive tillers more will be the yield and vice versa. Out of 36 hybrids, 17 hybrids showed significant positive standard heterosis. For number of unproductive tillers/ plant, standard heterosis ranged from $-50.00($ IR $72081 \mathrm{~A} \times$ Satya, IR 72081A $\times$ MTU 1010, IR 68902A $\times$ NLR 33358, IR $68902 \mathrm{~A} \times \mathrm{RNR}(\mathrm{RK}) 28, \mathrm{IR} 58025 \mathrm{~A} \times \mathrm{MTU} 1010, \mathrm{IR}$ $58025 \mathrm{~A} \times \mathrm{IR} 64$, IR $58025 \mathrm{~A} \times \mathrm{KNM} 118$, IR $58025 \mathrm{~A} \times$ Varalu and IR 58025A $\times$ RNR 15038) to 100.00 (IR 72081A $\times$ Rajendra), when compared with check PA 6129. Number of unproductive tillers/ plant is an important trait of hybrid which reduces the yield. Hence, heterosis in negative direction which implies less unproductive tillers/ plant is desirable for this trait. Out of 36 hybrids, nine hybrids showed significant negative standard heterosis. For flag leaf length, standard heterosis ranged from -16.88 (IR $72081 \times \mathrm{KNM} 118$ ) to 54.55(IR 68902A $\times$ Varalu), when compared with check PA 6129. Higher flag leaf length is a desirable feature of hybrid rice for efficient photosynthesis at and after flowering. Out of 36 hybrids, 25 hybrids showed significant positive standard heterosis. For flag leaf width, standard heterosis ranged from $-53.33($ IR $68902 \mathrm{~A} \times$ IR 64) to $0.00($ IR $72081 \mathrm{~A} \times \mathrm{RNR}(\mathrm{RK}) 28$ and IR $68902 \mathrm{~A} \times$ Rajendra), when compared with check PA 6129 (Table 2). Out of 36 hybrids, none of them showed significant positive standard heterosis. For spikelet fertility percentage, standard heterosis ranged from -4.53 (IR $58025 \mathrm{~A} \times$ Rajendra) to 8.00 (IR 58025A × MTU 1010), when compared with check PA 6129 . Out of 36 hybrids, four of them showed significant positive standard heterosis. For number of filled grains per panicle, standard heterosis ranged from -33.75 (IR 68902A $\times$ Satya) to 68.74 (IR 68902A $\times$ Rajendra), when compared with check PA 6129. Out of 36 hybrids, 17 hybrids showed significant positive standard heterosis. For grain yield per plant, standard heterosis ranged from -55.71 (IR 58025A $\times$ Rajendra) to 18.25 (IR $58025 \mathrm{~A} \times$ MTU 1010), when compared with check PA 6129 . Out of 36 hybrids, three hybrids showed signifi- 


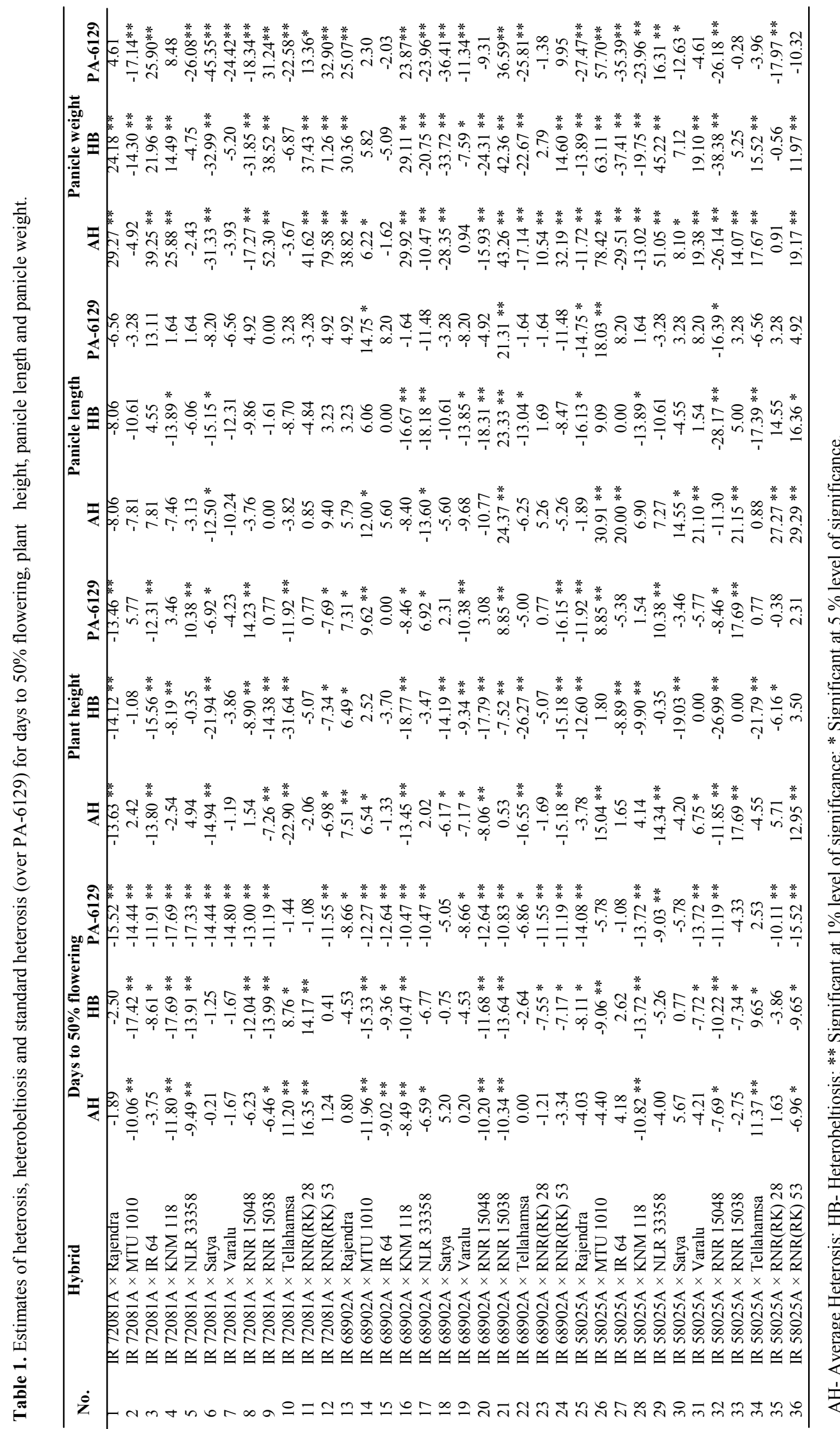




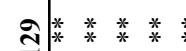

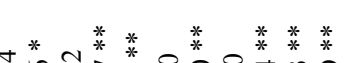

$+* * *$

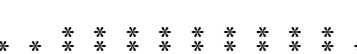

***

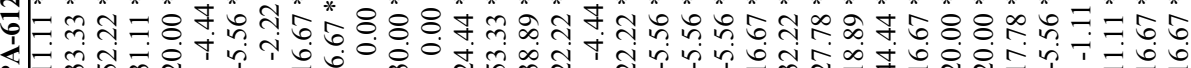

表

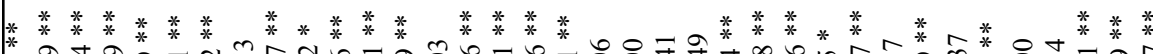

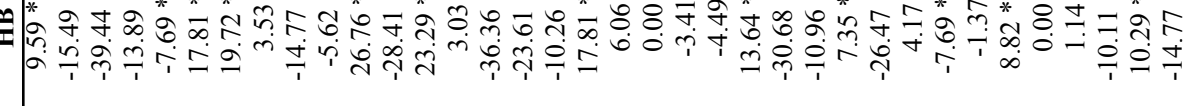

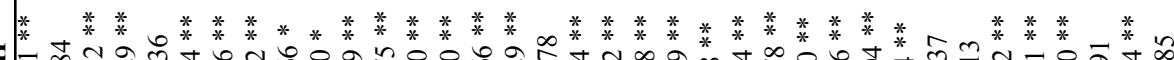

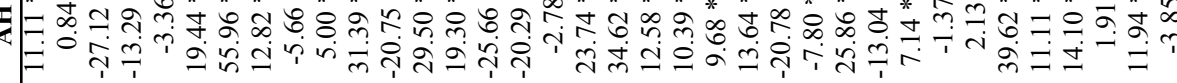

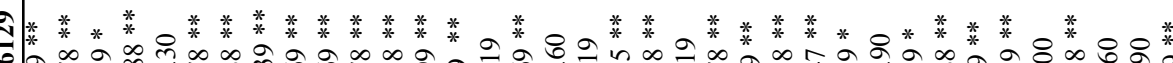

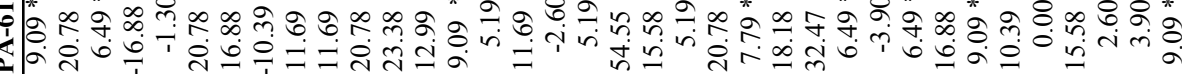

言

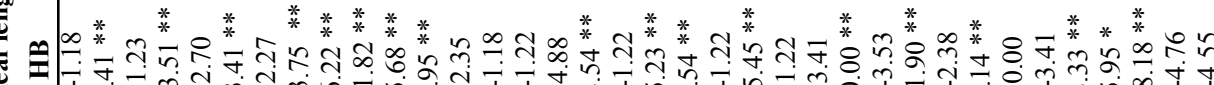
$\frac{200}{\Sigma}$

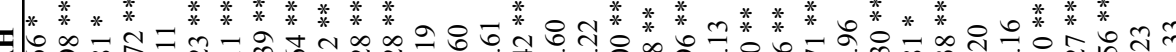

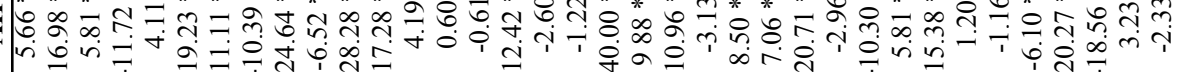

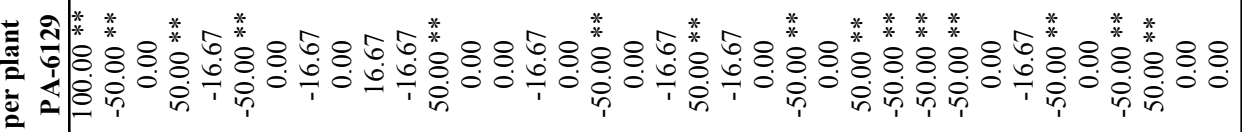

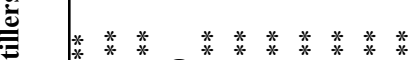

他 mं

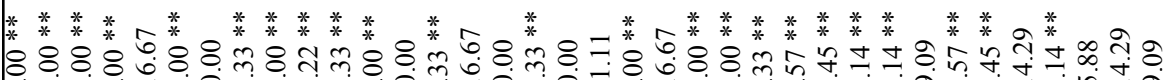

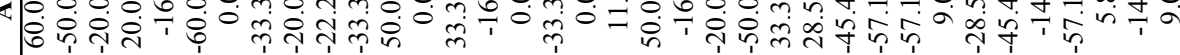

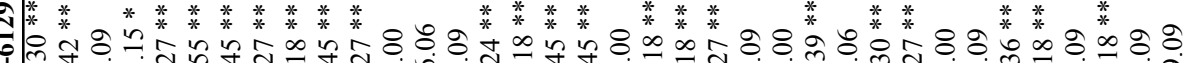

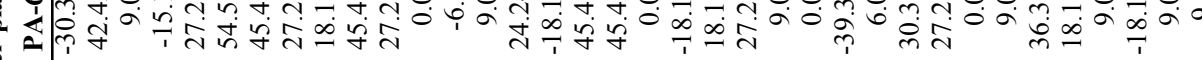

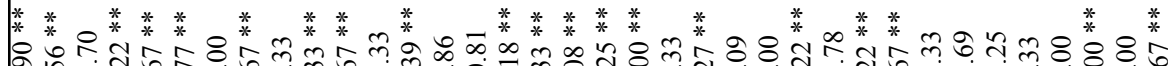

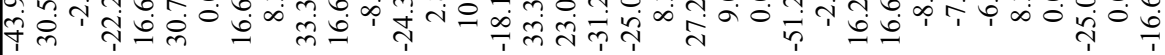

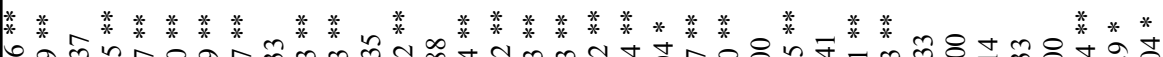

य)

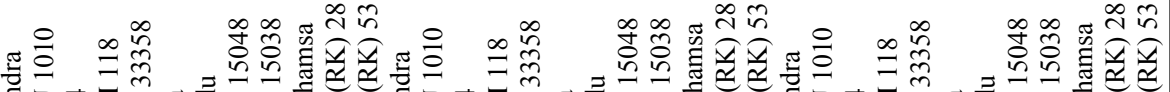

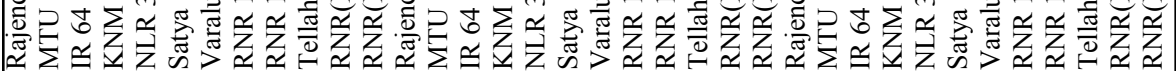

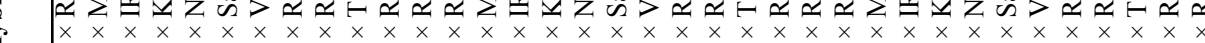

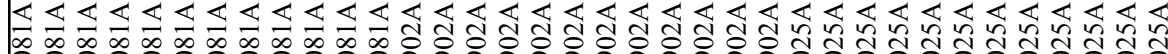

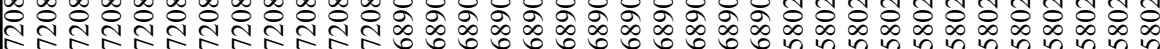

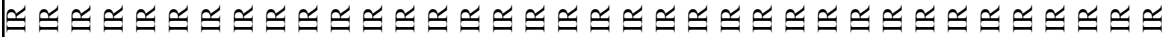


A. Srijan et al. / J. Appl. \& Nat. Sci. 8 (1) : $184-190$ (2016) 
cant positive standard heterosis. For productivity/day, standard heterosis ranged from -50.47 (IR 58025A $\times$ Rajendra) to 24.90 (IR 68902A $\times$ RNR 15038), when compared with check PA 6129 (Table 3).

Out of 36 hybrids, four hybrids showed significant positive standard heterosis. For 1000 grain weight, standard heterosis ranged from $-30.45($ IR 72081A $\times$ RNR $(\mathrm{RK}) 28)$ to 3.72 (IR 58025A $\times$ MTU 1010), when compared with check PA 6129. Out of 36 hybrids, none of the hybrids showed significant positive standard heterosis.

For grain length, standard heterosis ranged from -11.23 $($ IR $68902 \mathrm{~A} \times$ Varalu) to $17.50($ IR $58025 \mathrm{~A} \times \mathrm{RNR}$ (RK) 28), when compared with check PA 6129. Long grain type is most preferred so, positive significant standard heterosis is desirable. Out of 36 hybrids, 21 hybrids showed significant positive standard heterosis. For grain breadth, standard heterosis ranged from 20.64 (IR 72081A $\times$ RNR $(\mathrm{RK})$ 28) to 8.97 (IR 58025A $\times$ RNR 15048), when compared with check PA 6129 . Slender grain type is most preferred so, negative significant standard heterosis for grain breadth is desirable. Out of 36 hybrids, 12 hybrids showed significant negative standard heterosis. For grain length-breadth ratio, standard heterosis ranged from -15.50 (IR $72081 \mathrm{~A} \times \mathrm{RNR}(\mathrm{RK}) 53$ ) to $34.35($ IR $58025 \mathrm{~A} \times \mathrm{RNR}$ 15038), when compared with check PA 6129 (Table 4). Long/medium slender grain type is most preferred so, positive significant standard heterosis for LB ratio is desirable. Out of 36 hybrids, 16 hybrids showed significant positive standard heterosis.

Earlier researchers also reported character wise contribution of significant heterosis for grain yield per plant viz., through days to $50 \%$ flowering (plants numbered 19, 12-17, 19-25, 28, 29, 31, 32, 35 and 36), plant height (plants 1, 3, 6, 10, 12, 16, 19, 24, 25 and 32), panicle length (plants 14, 21 and 26) and number of filled grains per panicle (plants 1, 3, 4, 9, 11-14, 16, 20, 21, 23, 24, 26, 29, 31 and 33) by Saidaiah et al. (2012) and Kumari Priyanka et al. (2014);through panicle weight (plants 3, 9, 11 $-13,16,21,26$ and 29), flag leaf length (plants 1-3, 6, 7, 9 $-14,16,19,20,22-26,28-31,33$ and 36 ), spikelet fertility $\%$ (plants 3, 17, 26 and 29) and productivity/day (plants 3, 9, 21 and 26) by Saidaiah et al. (2012); through number of productive tillers per plant (plants 2, 5-11, 15, 17, 18, 21, 22, 27, 28, 31 and 32) by Gouri Shankar et al. (2010), Tiwari et al. (2011), Saidaiah et al.(2012) and Rukmini et al. (2014); through grain length (plants 1-3, 5, 6, 13, 18, $21,22,24-31$, and 33-36), grain breadth (plants 11, 13, $20,21,27,28,30,31,33,34$ and 36) and grain lengthbreadth ratio (plants 3, 11, 13, 21, 22, 25-31 and 33-36) by Sanjeev Kumar et al. (2010), Sanghera and Hussain (2012) and Dar et al. (2014). These findings explain the desirability of significant heterosis of various component characters in improving the grain yield.

\section{Conclusion}

The present study concluded that heterosis for grain yield per plant is mainly because of simultaneous manifestation of heterosis for yield component traits. Out of 36 hybrids studied, the significant standard heterosis for grain yield is observed in 3 hybrids, over best check PA 6129, viz., IR 58025A × MTU 1010 (18.25), IR 68902A $\times$ RNR 15038 (14.59) and IR $72081 \mathrm{~A} \times \mathrm{RNR} 15038$ (9.57). These three experimental hybrids are recommended for further evaluation over locations and seasons to study its performance, for large scale commercialization in Telangana.

\section{REFERENCES}

Dar, S.H., Rather, A.G., Najeeb, S., Zeerak, N.A., Shikari, A.B., Bhat, Z.A., Ahanger, M.A., Mir, S.D., Mushtaq Ahmad, Shahida Iqbal, Iram Saba and Hassan, G. (2014). Gene action and standard heterosis over environments in rice (Oryza sativa L.). Electronic Journal of Plant Breeding, 5(3): 360-370.

IIRR (Indian Institute of Rice Research). (2015). Draft Proceedings of $50^{\text {th }}$ Annual Rice Research Group Meetings, Rajendranagar, Hyderabad-500 030.

FAORAP and APSA (FAO Regional Office for Asia and the Pacific and Asia-Pacific Seed Association). (2014). Proceedings of the Regional Expert Consultation on "'Hybrid Rice Development in Asia: Assessment of Limitations and potential," Bangkok, Thailand.

Gouri Shankar, V., Ansari, N.A., Ilyas Ahmed, M. and Ramana Rao, P.V. (2010). Heterosis studies using thermosensitive genetic male sterile lines in rice. Oryza, 47(2): 100-105.

Kempthorne, O. (1957). An introduction genetic statistics. John Wiley and Sons, Inc: New York.

Krishna Veni, B. and Shobha Rani, N. (2003). Heterosis for yield and yield attributes in aromatic rice. Madras Agricultural Journal, 90: 10-12.

Kumari Priyanka, Jaiswal, H.K. and Waza, S.A. (2014). Combining ability and heterosis for yield, its component traits and some grain quality parameters in rice (Oryza sativa L.). Journal of Applied and Natural Science, 6 (2): 495-506

Liang, G.H., Reddy, C.R and Dayton, A.D. (1971). Heterosis, inbreeding depression and heritability estimates in a systematic series of grain sorghum genotypes. Crop Science, 12: 400-411.

Raju, Ch. D., Sudheer Kumar, S., Raju, Ch. S and Srijan, A. (2014). Combining ability studies in the selected parents and hybrids in rice (Oryza sativa .L). International Journal of Pure and Applied Bioscience, 2 (4): 271-279.

Rukmini Devi, K., Parimala, K. and Cheralu, C. (2014). Heterosis for yield and quality traits in rice (Oryza sativa L.). The J.Res. ANGRAU, 42(1): 1-11.

Saidaiah, P., Ramesha, M.S. and Sudheer Kumar, S. (2012). Evaluation of CMS system based rice hybrids for heterosis over locations. Oryza, 49(3): 153-162.

Sanghera, G.S. and Hussain, W. (2012). Manifestation of heterosis for yield and component traits in rice(Oryza sativa L.) under temperate environment. $L S$ - An International Journal of Life Sciences, 1(3): 233-237.

Sanjeev Kumar, Singh, H.B., Sharma, J.K. and Sood, S. (2010). Heterosis for morpho-physiological and qualitative traits in rice. Oryza, 47(1): 17-21.

Tiwari, D.K., Pandey, P., Giri, S.P. and Dwivedi, J.L. (2011). Heterosis studies for yield and its components in rice hybrids using CMS system. Asian Journal of Plant Sciences, 10: 1, 29-42. 